\title{
Microsatellite Stability Assessment
}

National Cancer Institute

\section{Source}

National Cancer Institute. Microsatellite Stability Assessment. NCI Thesaurus. Code C139286.

An assessment of the variability in length of an individual's microsatellite sequences;

microsatellite length instability may be due to mismatch repair protein mutation. 